\title{
Welcome to the
}

\section{Canadian Respiratory Journal}

T $t$ is with pride and homour that I intreduce the first issuc of the oflicial journal of the Canadian Thoracic Society (CTS) - the Canadian Respiratory Journal. This new journal has risen from a long history of excellence in respiratory research in Canada.

On a per capita basis, Canada has the strongest respiratory research community in the

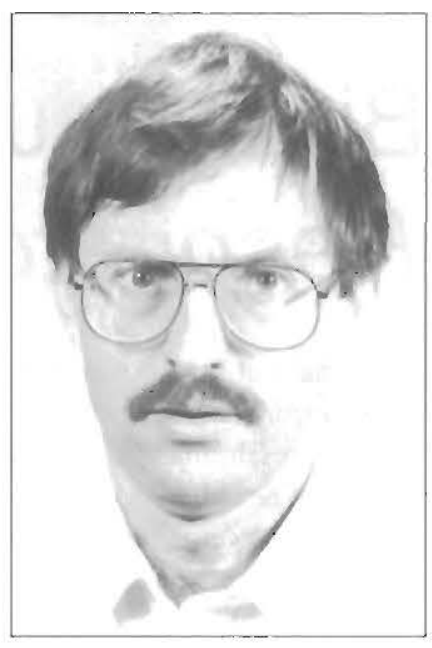
world. The importance of respiratory research in Canada is exemplified by the fact that one of the five biomedical Networks of Centres of Excellence of Canada is the Respiratory Health Nelwork of Centres of Excellence. This network, which brings together over 60 outstanding respiratory researchers from icross Canada, is presided over by one of the world’s most prominent respiratory researchers. Dr Peter Macklem. I3ctween 1965 indsd 1978, out of the 1000 most cited scientists, three were respirologists, two of lhem Camadians.

A number of Canadians have held ind continte to hold international leadership roles in respiratory medicinc. Iing example, the only non-American president of the American Thoracic Sociely (ATS) wals I)r Clarence Guenter. at Canadian. Over the years, Canadians have contributed excellent research material in respiratory health. The participation of Canadians to the ATS annual mecling has alwalys becu oulstanding. In 194)3, 345 Canadian pakpers were presented at the San Francisco ATS meeting.

The medical section of the Canadian Lung Association (CLA) was formed in 1948. From this section, the CTS wat started in 1958, two years before the formation of the ATS. The society has, since its foundation, greatly encouraged and contributed to respiratory health research. From 1963 to 1982 funding was made available from the CLA for the CTS to fund both research grants and fellowships. In 1982, in view of the great need to train new researchers, llse funding was channelled to fellowships only, the provincial association continuing 10 support research projccts. In I993 the CTS joined forces with the Medical Researcls (ouncil (MRC) to introduce joint CLA/MRC fellowships for eight new young trainees each year ( 10 a maximums of 20 trainees at a given time), and to sponsor a new scholarship progranı. Over the past 20 years the (TS and CLA have helped train 139 respirologists and basic science researchers. OI these, many have become world renowned researchers, including Moira Chan-Yeung, Jim Dusminn, Paul Man, Maznel Jordina and Douglas Bradley.

Besides providing funding for fellows and scholiars, the CTS plays an active role in continuing medical education. The society holds its annual scientific meeting jointly with the Royal College of Physicians of Canada and publishes position papers on a variety of respiratory health issues. In collaboration with the CLA, the CTS is also embarking on an asthma education and research program, addressing social issues such as smoking cessation, environmental air quality and the recent resurgence of tuberculosis.

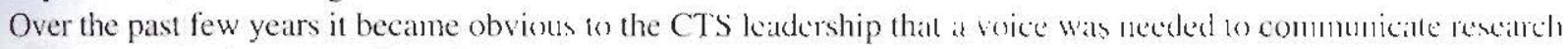

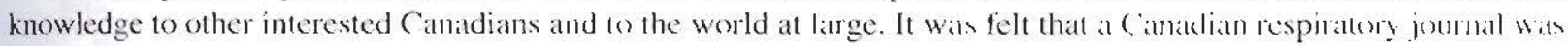
not only feasible, but with the level of excellence of (anadian respiratory research, lle joumal would beconse very successful. Special recognition for his contribution to the founding of the Canadian Rexpiratory. Inumal must be given to my predecessur. Dr Divid Cottom, president of the (TS in [992-93. Ilis comviction for the need of this journal, his continuous drive and his abilities to lead onliess in lhis venture are responsible lur the realization of this step forward in Canadian respiralory research.

With an outstanding world renowned cditorial board and a respected publishing compriny, we feel very conlidenll that Canadian and intemational researchers will take interest in reading the Canadian Respiratory Journal and pride in submitting to it world class manuscripts for publication. 


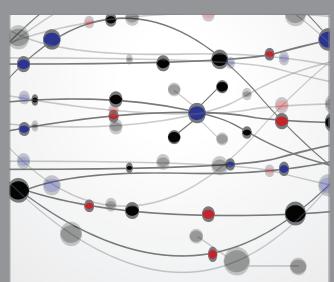

The Scientific World Journal
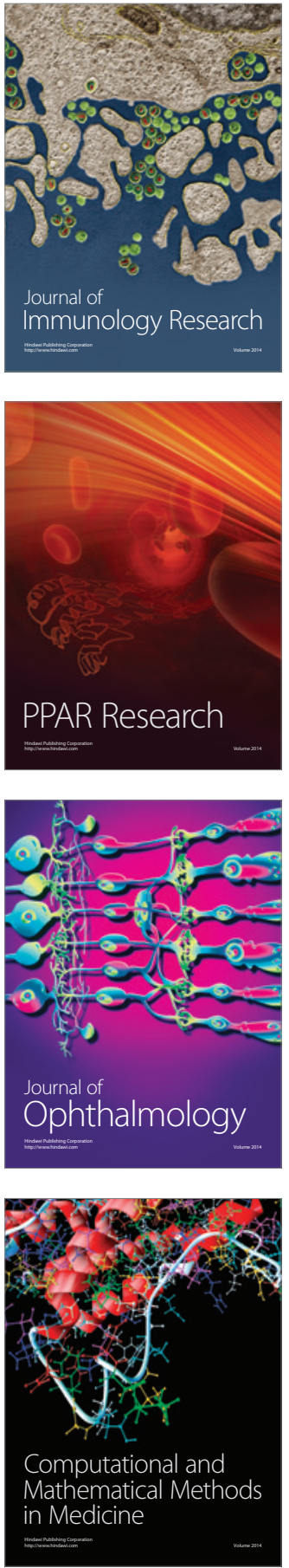

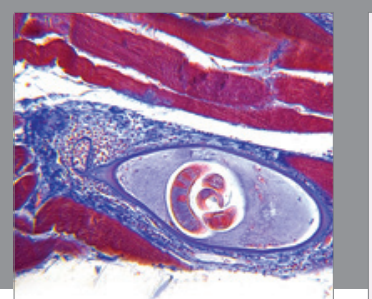

Gastroenterology Research and Practice

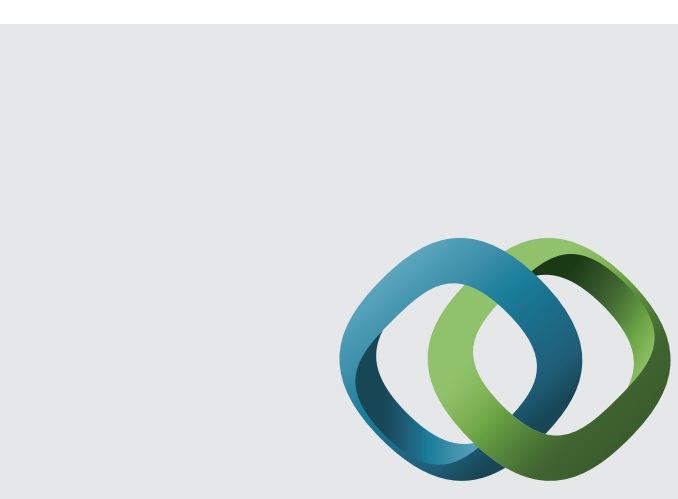

\section{Hindawi}

Submit your manuscripts at

http://www.hindawi.com
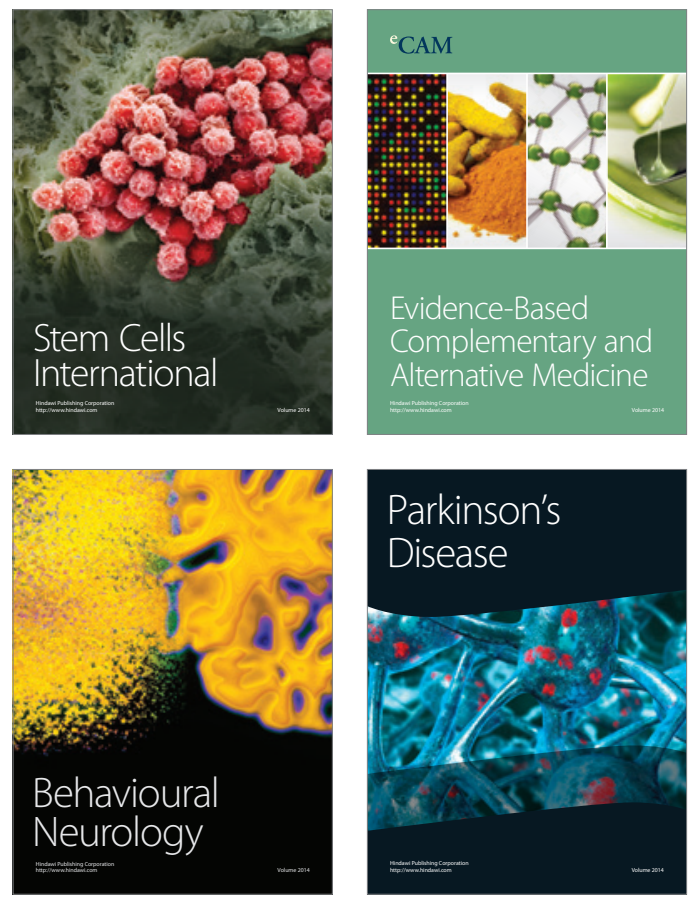
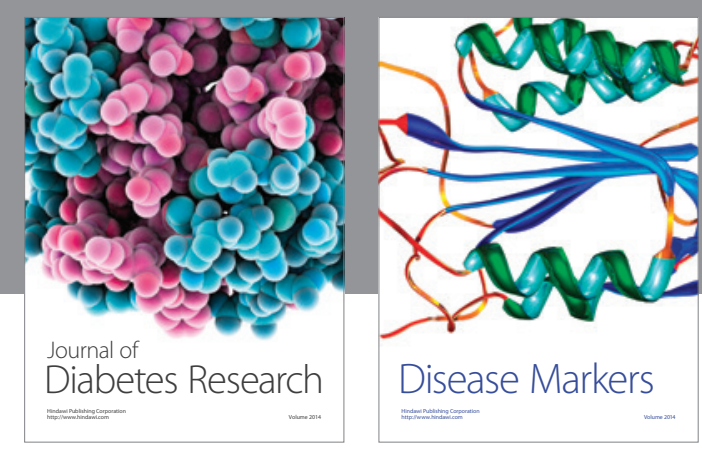

Disease Markers
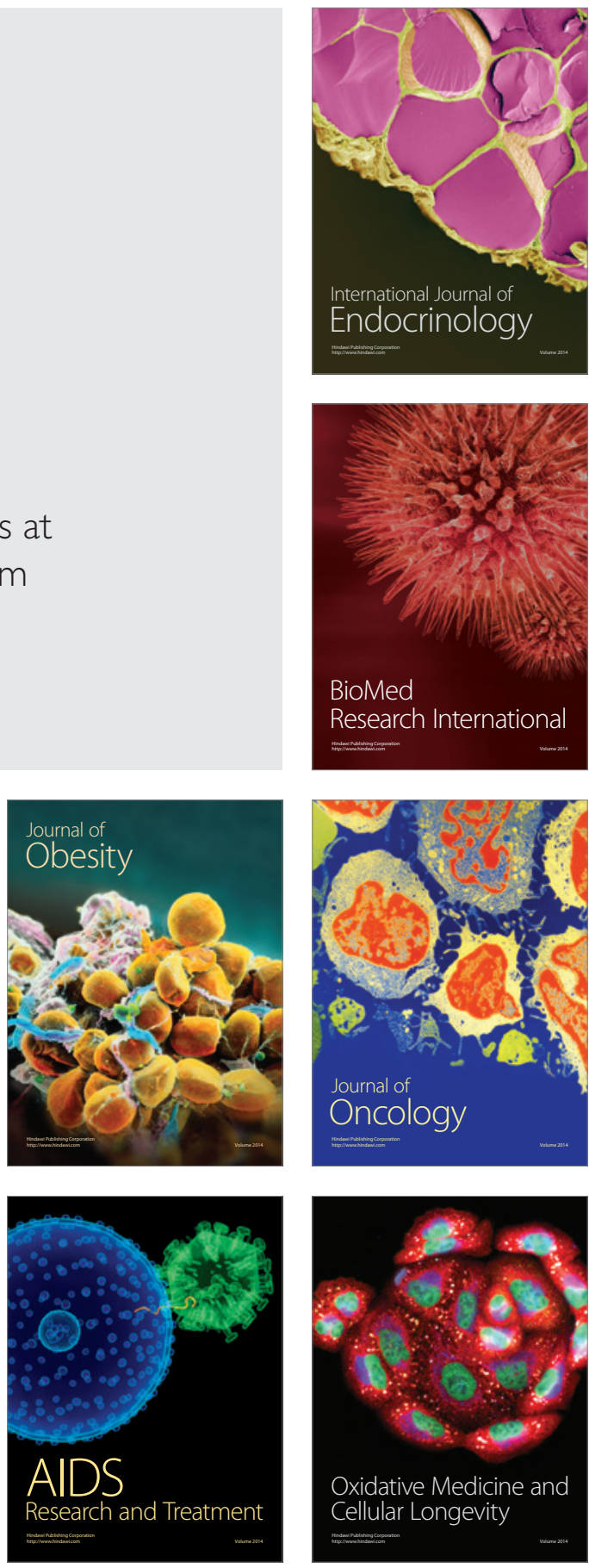